\title{
Prevalence and pattern of renal disease in eastern Libya
}

\author{
A Y ELZOUKI, F AMIN, AND O P JAISWAL \\ Department of Paediatrics, Faculty of Medicine, University of Garyounis, Benghazi, Libya
}

SUMMARY A prospective study was conducted to identify the pattern and aetiology of kidney disease in children living in eastern Libya. A total of 343 patients was studied, representing $3 \%$ of annual admissions to the children's hospital. The major renal diseases were post-streptococcal glomerulonephritis (in 116), acute renal failure (in 93), and idiopathic nephrotic syndrome (in 65). Less common diseases were tubular transport defect (in 3) and end-stage renal disease (in 3). The mortality rate (excluding neonates) was below $1 \%$. The pattern of kidney disease referred to this hospital in Libya was different from that reported in other parts of Africa.

Reports on the spectrum of kidney disease in children living in Africa are sparse ${ }^{1}$ although there are some on specific kidney diseases. ${ }^{2-5}$ As far as the temperate regions of north Africa are concerned there is a lack of information on the pattern of kidney disease.

A 26-month prospective study of renal disease was undertaken in children admitted to the El-Fatah Children's Hospital, Benghazi, or followed up there. The hospital is the only referral centre for a population of about one million people.

The study concentrated on the clinical aspects of renal disease in childhood. Data are given on the prevalence of kidney disease in children from birth to age 14 years, its pattern and aetiological significance, and the age- and sex-related patterns of renal disease in this area.

\section{Patients and methods}

The study was carried out between January 1980 and February 1982 on children aged 14 years and below, with signs and symptoms of renal disease. Each child had been admitted to El-Fatah Children's Hospital or had been followed up there as an outpatient. The hospital is the referral centre for the whole of the eastern and central part of Libyan Jamahiria. Selective referral of the more seriously ill patients may well be present but no other selective bias is known to have been introduced. We believe that the data are representative of the general distribution of renal disease serious enough to warrant hospital referral; it probably underestimates such conditions as urinary tract infections, which will have been treated elsewhere.

\section{Definitions}

Nephrotic syndrome. The presence of heavy proteinuria $\left(>40 \mathrm{mg} / \mathrm{h}\right.$ per $\left.\mathrm{m}^{2}\right)$ determined quantitatively, accompanied by hypoalbuminaemia (serum albumin $<2 \cdot 5 \mathrm{~g} / 100 \mathrm{ml}){ }^{6}$

Acute glomerulonephritis. Haematuria or red blood cell casts accompanied by at least two of the following: oedema, decreased glomerular filtration rate, or hypertension. ${ }^{7}$

Post-streptococcal acute glomerulonephritis. Acute glomerulonephritis with low $\mathrm{C} 3$, and the presence of a positive throat or skin culture for $\beta$-haemolytic streptococci, or rising ASO or anti DNA-ase titres. ${ }^{8} 9$

Urinary tract infection. Symptomatic patient with a single organism with bacterial count $>10^{5}$ in a clean catch urine specimen, or any number of bacteria in suprapubic aspiration.

Acute renal failure. An acute reduction in renal function associated with a persistent increase in serum creatinine levels to $>2 \mathrm{mg} / 100 \mathrm{ml}(>177$ $\mu \mathrm{mol} / \mathrm{l})$ despite the absence or correction of dehydration, haemodynamic and mechanical causes of reduced renal function. ${ }^{10-13}$

Other definitions have been given previously. ${ }^{14-17}$

The following clinical and laboratory information were recorded and analysed (1) Demographic characteristics, age, and gender. (2) Family history of renal disease or high blood pressure. (3) Signs and symptoms. (4) Laboratory examination including 
urine analysis, urine culture, urinary protein excretion, routine blood chemistry and haematology, acid base profile, serum and urine osmolality, urine electrolytes, throat culture for streptococcus, antistreptolysin $O$ titre, serum complement (C3 and C4), antinuclear antibodies, IgG, IgM, IgA, radiological examination (intravenous pyelography, micturating cystourethrogram), ultrasonic examination, kidney biopsy (light and electron microscopical examination).

\section{Results}

Renal diseases in children represent a small but significant proportion of total admissions to the children's hospital: $139(2 \cdot 8 \%)$ of 5054 in 1980, and $169(3.3 \%)$ of 5238 in 1981.

The renal diseases diagnosed in the 343 patients are summarised in Table 1. Primary renal diseases were more common than systemic ones with renal involvement. Post-streptococcal acute glomerulonephritis was the most common, and represented nearly one-third of all cases. There was a male to female ratio of approximately $3: 2$. The mean age was 7.1 (range 1.5-13) years. Acute glomerulonephritis was much more often associated with streptococcal pharyngeal infection $(80 \%)$ than with streptococcal skin infection $(20 \%)$.

Idiopathic nephrotic syndrome, diagnosed in 65 patients, was the most common cause of the

Table 1 Clinical classification and aetiology of 343 cases of renal disease in children (1980-82) Benghazi

\begin{tabular}{lc}
\hline & Number of cases \\
\hline Acute glomerulonephritis (138 cases) & 116 \\
Post-streptococcal & 1 \\
Post-pneumococcal & 1 \\
Post-varicella & 1 \\
Systemic lupus erythematosus & 8 \\
Henoch-Schönlein syndrome & 4 \\
Rapidly progressive glomerulonephritis & 7 \\
Unknown & \\
& \\
Nephrotic syndrome (71 cases) & 65 \\
Idiopathic & 1 \\
Henoch-Schönlein & 3 \\
Post-streptococcal & 1 \\
Cyanotic heart disease & 1 \\
Unknown & 34 \\
Urinary tract infection & 7 \\
Congenital malformations of urinary tract & 3 \\
Tubular transport defect & 3 \\
Isolated haematuria & 1 \\
Isolated proteinuria & $93 *$ \\
Acute renal failure & 3 \\
Chronic renal failure & 4 \\
Urinary lithiasis & 2 \\
Kidney tumours & \\
* & \\
\hline id &
\end{tabular}

*16 patients were included in acute glomerulonephritis group.
Table 2 Idiopathic nephrotic syndrome (65 cases)

\begin{tabular}{lcc}
\hline & Boys & Girls \\
\hline All cases & 36 & 29 \\
Steroid responders & 35 & 29 \\
Steroid non-responders & 1 & 0 \\
\hline
\end{tabular}

nephrotic syndrome $(92 \%)$. Of the 65 patients treated with prednisone, 64 achieved remission (Table 2) and the one who did not respond had a renal biopsy showing mesangial proliferative glomerulonephritis. Forty-six patients relapsed after responding to prednisone, $22(48 \%)$ of whom frequently relapsed, at least two relapses in 6 months. The sex ratio of the relapsers, whether frequent or infrequent, was similar to that for the group as a whole. All frequent relapsers had renal biopsies before treatment with cyclophosphamide or chlorambucil, and were diagnosed as having minimal change nephrotic syndrome.

Table 3 shows the main aetiological groups of acute renal failure. Only patients with acute glomerulonephritis who had serum creatinine levels $\geq 2$ $\mathrm{mg} / 100 \mathrm{ml}(\geq 177 \mu \mathrm{mol} / \mathrm{l})$ were included (range 2-3.5 mg/100 ml; 177-310 $\mu \mathrm{mol} / 1$ ). Dehydration is a common reason for admission to hospital. Generally patients respond promptly to correction of water and electrolyte deficits. The 55 patients with acute renal failure had failed to respond to fluid challenge, rehydration, and frusemide. They had severe oliguria (urine output less than 0.5 $\mathrm{ml} / \mathrm{kg}$ per hour), a rising serum creatinine level (highest $5 \mathrm{mg} / 100 \mathrm{ml} ; 442 \mu \mathrm{mol} / \mathrm{l}$ ), and other laboratory evidence of tubular damage. Prognosis was excellent in this group. Only 3 patients needed peritoneal dialysis and, with the exception of one who died, all made a complete recovery. In neonates acute renal failure was related mainly to hypoxia and septicaemia and most of them had pulmonary insufficiency and assisted ventilation. None of the patients with acute glomerulonephritis needed dialysis and all made a good recovery. Of the 5 cases of rapidly progressive glomerulonephritis, one patient with systemic lupus erythematosus died and the others recovered completely. Three patients were diagnosed to have end-stage renal disease. In one 14-year-old patient, renal biopsy showed end-stage glomerulonephritis. In another patient in this group, 3-years old, one kidney was hydronephrotic and the other dysplastic with an associated urethral stricture. Currently 2 patients are on haemodialysis and one is on chronic peritoneal dialysis.

Escherichia coli was the most common cause of symptomatic urinary tract infection $(72 \%)$. The 
Table 3 Aetiology of acute renal failure in 93 children

\begin{tabular}{|c|c|c|c|c|}
\hline \multirow[t]{2}{*}{ Aetiology } & \multicolumn{2}{|c|}{ Children } & \multirow[b]{2}{*}{ Dialysis } & \multirow[b]{2}{*}{ Died } \\
\hline & No & $\%$ & & \\
\hline Haemolytic uraemic syndrome & 1 & (1) & 1 & 0 \\
\hline Acute glomerulonephritis & 11 & (12) & $\mathbf{0}$ & 0 \\
\hline $\begin{array}{l}\text { Rapidly prot ressive } \\
\text { glomerulonephritis }\end{array}$ & 5 & (5) & 1 & 1 \\
\hline \multicolumn{5}{|c|}{ Acute tubular necrosis ( $>1$ month of age) } \\
\hline After dehydration & 55 & (59) & 2 & 0 \\
\hline Septicaemia & 5 & (5) & 2 & 0 \\
\hline After congestive heart failure & 2 & (2) & 0 & 0 \\
\hline \multicolumn{5}{|l|}{ Acute tubular necrosis (neonates) } \\
\hline Septicaemia & 7 & (8) & 1 & 2 \\
\hline Hypoxia and hypotension & 7 & (8) & 2 & 4 \\
\hline
\end{tabular}

female to male ratio was approximately $3: 1$. Of the 11 boys with symptomatic urinary tract infection, 3 have congenital anomalies of the urinary tract, and 2 have vesical stones. Of the systemic diseases responsible for renal functional abnormalities Henoch-Schönlein syndrome was associated with a good prognosis. Eight of the 9 patients had only microscopic haematuria, mild proteinuria, normal glomerular filtration rate, no hypertension, and on follow-up ranging from 1 to 26 months there was no deterioration of renal function. One patient had nephrotic syndrome but refused renal biopsy; when he was followed up 27 months later he went into spontaneous remission which has so far lasted 15 months.

Three patients were diagnosed as having tubular transport defects: one distal renal tubular acidosis, one Liddle's syndrome, and one mixed renal tubular acidosis. All 3 presented clinically with failure to thrive, and weight and height below the 3rd centile.

Apart from neonates with acute renal failure, only 3 patients died. One patient with systemic lupus erythematosus complied poorly. She had a severe relapse and died from sepsis and acute renal insufficiency. One patient died in whom nephrotic syndrome was complicated by multiple thrombembolic phenomena. One patient with postdehydration acute renal failure died after congestive heart failure.

\section{Discussion}

The findings of a prospective analysis of renal disease in children living in eastern Libya are described. In each child the diagnosis of renal disease had been confirmed.

The most common diagnosis was that of poststreptococcal acute glomerulonephritis and comprised $33.8 \%$ of renal diseases and $1 \%$ of all hospital admissions. In this respect our findings are similar to many reviews of renal disease in children in other parts of the world. ${ }^{18}$

In our study acute glomerulonephritis was far more often associated with streptococcal pharyngeal infection $(80 \%)$ than with streptococcal skin infection, while in nearly every other part of Africa the reverse seems to be true. ${ }^{1519}$ This may be because our climate is temperate. Idiopathic nephrotic syndrome is an important renal disease in children, being responsible for $19.2 \%$ of admissions to the renal unit in this area. The data do not allow an accurate measurement of the incidence of nephrotic syndrome but it seems likely that it is appreciably greater than that found by some other authors. ${ }^{20}$ However, it should be noted that the population structure in Libya is heavily weighted towards the younger age groups; $51 \%$ of estimated mid year population of resident Libyans were children under age 15 years. ${ }^{21}$ This will increase the incidence of any disease affecting the young, as steroid-sensitive nephrotic syndrome does. Steroid responders comprised $98.5 \%$ which is higher than reported by the International Study of Kidney Disease in Children (of $\mathbf{4 3 3}$ children only $77.6 \%$ responded to steroid), and higher than in other reports from the UK, ${ }^{22}$ with only $75 \%$ responding to steroid therapy. In east and west Africa the nephrotic syndrome often occurs in association with Plasmodium malariae infection, 24 with poor response to steroids. In a study of nephrotic syndrome from South Africa ${ }^{23}$ only $14.3 \%$ of blacks and $52 \%$ people of Indian origin responded to steroid.

In the present study the mean age for steroid responders was 5.8 years; $24 \%$ of them were younger than 3 years and $16.6 \%$ were older than 10 years, while in the International Study of Kidney Disease in Children half the children were younger than 3 years and only $7.8 \%$ older than 10 years. The ratio of males to females was $1 \cdot 2: 1$ while in three other series $^{622} 24$ it ranged from $2 \cdot 0: 1$ to $2 \cdot 6: 1$.

The main aetiology of acute renal failure in our study was dehydration. The margin between the prerenal failure of dehydration and the true renal failure of acute tubular necrosis is difficult to define but these patients seemed to be examples of the latter condition. Acute glomerulonephritis was the second most common cause of acute renal failure; none needed peritoneal dialysis and all recovered completely. Major surgical procedures and extensive trauma are important causes of acute renal failure, ${ }^{12}$ but such patients are not managed in the El-Fatah Children's Hospital. It is likely that the prevalence of urinary tract infection in the general population is much greater than these statistics suggest, and it is considered to occur as a subclinical disease in many 
females. However, our patients with symptomatic urinary tract infection often presented to us with gross haematuria which can be confused with other renal diseases, and in boys urinary tract infection is the usual clinical presentation for congenital anomalies of urinary tract or urinary lithiasis. These findings are consistent with previous reports. ${ }^{25}$ If acute renal failure in neonates is excluded, only 3 died out of 329 children with renal disease of various types. This makes the overall mortality rate lower than $1 \%$.

\section{Conclusion}

This study gives detailed information about the pattern of renal disease in children in the temperate part of Africa.

It is concluded that (1) The pattern of kidney disease in Libya is different from that in other parts of Africa. (2) Post-streptococcal acute glomerulonephritis is the most common renal disease of childhood, and accounted for about $1 \%$ of all hospital admissions for children. (3) Urinary tract infection in boys requires investigation as most such patients will be found to have congenital malformations of urinary tract or urinary lithiasis. (4) The idiopathic nephrotic syndrome in this area differed from that previously reported in that the mean age was higher, the male:female ratio was lower, and more than $98 \%$ of children responded to steroids. (5) With effective management renal diseases of childhood have a good prognosis. The mortality in this series was less than $1 \%$.

\section{References}

1 Hendrickse R G. Epidemiology and prevention of kidney disease in Africa. Symposium on renal disease in the tropics. Trans R Soc Trop Med Hyg 1980; 74: 8-16.

2 Gilles H M, Hendrickse R G. Nephrosis in Nigerian children. Role of Plasmodium malariae and effect of antimalarial treatment. $\mathrm{Br} \mathrm{Med} J$ 1963; i: 27-31.

3 Hendrickse R G, Glasgow E F, Adeniyi A, White R H R, Edington G M, Houba V. Quartan malarial nephrotic syndrome. Collaborative clinicopathological study in Nigerian children. Lancet 1972 ; i: 1143-9.

4 Kibukamusoke J W, Hutt M S R, Wilkes N E. The nephrotic syndrome in Uganda and its association with quartan malaria. Q J Med 1967; 36: 393-408.

5 Axemo P, Freij L, Hadgu P, et al. Streptococcal types in impetigo and acute glomerulonephritis among children in Addis Ababa. Scand J Infect Dis 1976; 8: 161-4.

6 International Study of Kidney Disease in Children. Report: Nephrotic syndrome in children: prediction of histopathology from clinical and laboratory characteristics at time of diagnosis. Kidney Int 1978; 13: 159-65.

7 Coe F L. The clinical and laboratory assessment of the patient with renal disease. In: Brenner B M, Rector F C, Jr, eds. The kidney. Philadelphia: Saunders, 1976: 765-805.

8 Potter E V, Abidh S, Sharrett A R, et al. Clinical healing two to six years after poststreptococcal glomerulonephritis in Trinidad. N Engl J Med 1978; 298: 767-72.

9 Kaplan B S, Esseltine D. Thrombocytopenia in patients with acute post-streptococcal glomerulonephritis. $J$ Pediatr 1978; 93: 974-6.

10 Anderson R J, Linas S L, Berns A S, et al. Nonoliguric acute renal failure. $N$ Engl J Med 1977; 296: 1134-8.

11 Espinel $\mathrm{C} \mathrm{H}$. The FeNa test use in the differential diagnosis of acute renal failure. JAMA 1976; 236: 579-81.

12 Hodson E M, Kjellstrand C M, Mauer S M. Acute renal failure in infants and children, outcome of 53 patients requiring hemodialysis treatment. $J$ Pediatr 1978; 93: 756-61.

13 Dauber I M, Krauss A N, Symchych P S, Auld P M. Renal failure following perinatal anoxia. $J$ Pediatr 1976; 88: 851-5.

14 Rodriguez-Soriano J. The renal regulation of acid base balance and the disturbances noted in renal tubular acidosis. Pediatr Clin North Am 1971 ; 18: 529-43.

15 Gardner J D, Lapey A, Simopoulos A P, Bravo E L. Abnormal membrane sodium transport in Liddle's syndrome. J Clin Invest 1971 ; 50: 2253-8.

16 Counahan $\mathrm{R}$, Winterborn $\mathrm{M} \mathrm{H}$, White $\mathrm{R} \mathrm{H} \mathrm{R}$, et al. Prognosis of Henoch-Schönlein nephritis in children. Br Med J 1977; ii: 11-4.

17 O'Neil W M, Jr, Etheridge W B, Bloomer H A. High dose corticosteroids, their use in treating idiopathic rapidly progressive glomerulonephritis. Arch Intern Med 1979; 139: 514-8.

18 Travis $\mathrm{L}$ B. Acute postinfectious glomerulonephritis. In: Edelmann C M, Jr, ed. Pediatric kidney disease. Boston: Little Brown, 1978: 611-31.

19 Wesley A G, Scragg J N, Rubidge C J, Wallace H L. The racial incidence of disease in hospital children in Durban. S Afr Med J 1967; 41: 332-5.

20 Arneil G C. 164 children with nephrosis. Lancet 1961; ii: $1103-10$.

21 Abudejaja A, Malhotra S L, Khan M A. Incidence of childhood cancers in Benghazi during 1977. Garyounis Med J 1980; 3: 13-7.

22 White R H R, Glasgow E F, Mills R J. Clinicopathological study of nephrotic syndrome in childhood. Lancet $1970 ;$ i: $1353-9$.

23 Adhikari M, Coovadia H M, Loening W E K. The nephrotic syndrome in children. $S$ Afr Med $J$ 1976; 50: 39-43.

24 Habib R. Primary nephrotic syndromes. In: Royer P, Habib R, Mathieu H, Broyer M, eds. Pediatric nephrology. Philadelphia: Saunders, 1974: 259-60.

25 Kunin C M. Management of urinary tract infection. In: Kunin C M, ed. Detection, prevention, and management of urinary tract infections, third edition. Philadelphia: Lea \& Febiger, 1979: 286, 318.

Correspondence to $\mathrm{Dr}$ Abdelaziz $\mathrm{Y}$ Elzouki, Department of Paediatrics, Faculty of Medicine, University of Garyounis, PO Box 1451, Benghazi, Libya.

Received 14 October 1982 